\title{
Predicting microbial nitrate reduction pathways in coastal sediments
}

\author{
Christopher K. Algar*, Joseph J. Vallino \\ Marine Biological Laboratory, Ecosystem Center, Woods Hole, Massachusetts 02543, USA
}

\begin{abstract}
We present an ecosystem model that describes the biogeochemistry of a sediment nitrate reducing microbial community. In the model, the microbial community is represented as a distributed metabolic network. Biogeochemical pathways are controlled through the synthesis and allocation of biological structure that serves to catalyze each process. Allocation is determined by way of a thermodynamically constrained optimization according to the principle of maximum entropy production (MEP). According to the MEP principle, ecosystems will organize so as to maximize the dissipation of free energy based upon the available resources (nutrients and electron donors and acceptors). In the model, 3 nitrate reduction pathways, viz. heterotrophic denitrification, anammox, and dissimilatory nitrate reduction to ammonium, compete for electron acceptors (nitrate and nitrite). The model predicts switches in the dominant nitrate cycling pathways based upon the ratio of carbon to nitrate supply. An advantage of this approach over a traditional organism-centric kinetic approach is that the Monod growth parameters, maximum uptake rate $\left(v_{\max }\right)$, and half saturation $\left(k_{\mathrm{M}}\right)$ constants are determined during the optimization procedure as opposed to parameters specified a priori. Such a model is therefore useful for applications where these kinetic parameters are unknown and difficult to measure, such as the marine subsurface, or when ecosystems undergo large-scale environmental perturbations resulting in shifts in the dominant organisms.
\end{abstract}

KEY WORDS: Denitrification - Anammox - DNRA - Diagenesis - Maximum entropy production · Biogeochemistry $\cdot$ Ecosystem modeling

\section{INTRODUCTION}

Microbes are responsible for many of the transformations involved in global biogeochemical cycles. In an Earth systems view, these microbes are performing as molecular machines, working to catalyze chemical reactions at rates several orders of magnitude above the background abiotic rate (Falkowski et al. 2008). Understanding the functioning and interaction of these 'machines' with the environment is a major goal of microbial ecology and is necessary for predicting which biogeochemical reactions are expressed and their rates (Konopka 2009).

As humans continue to perturb global biogeochemical cycles to ever greater degrees, the need to develop quantitative models capable of predicting changes in

*Corresponding author: calgar@mbl.edu biogeochemistry due to anthropogenic perturbations increases. For example, over the last century, humans have continued to perturb the global nitrogen cycle through large inputs of nitrogen, mostly in the form of nitrate (Galloway et al. 2004). Nitrogen is often a limiting nutrient, and export of excess nitrogen to coastal waters is a contributor to increased eutrophication and the development of hypoxic zones (Rabalais et al. 2001) and harmful algal blooms (Paerl et al. 2002). Fortunately, microbial processes in coastal sediments can remove much of the added nitrogen, ameliorating these effects (Seitzinger 1988). Under anaerobic conditions, bacteria convert $\mathrm{NO}_{3}{ }^{-}$to less biologically available $\mathrm{N}_{2}$ through the processes of heterotrophic denitrification (hereafter referred to as denitrification) and the newly discovered anammox process (Tham-

() The authors 2014. Open Access under Creative Commons by Attribution Licence. Use, distribution and reproduction are unrestricted. Authors and original publication must be credited. 
drup \& Dalsgaard 2002). However, these are not the only nitrate reduction pathways, as $\mathrm{NO}_{3}{ }^{-}$can also be reduced to ammonium through dissimilatory nitrate reduction to ammonium (DNRA). The ammonium produced remains readily bioavailable and can be recycled to the overlying water column, further contributing to primary production. It is necessary to understand the response of the microbial communities carrying out these competing processes in order to predict the effects of excess anthropogenic nitrogen on the coastal environment.

While there are sophisticated global circulation models to describe the relevant physical processes, the ability to model the biological response and its feedback on biogeochemical cycles lags behind. A primary reason for this lack of sophistication is an insufficient understanding of the fundamental principles controlling the organization of the microbial communities carrying out biogeochemical processes.

When attempting to model the biogeochemistry of a microbial ecosystem, there are essentially 2 opposing end member views that may serve as a framework. The first is the organism-centric view. In this view, it is the presence or absence of specific organisms that selects which biogeochemical reactions are present and their reaction rates. Emphasis is placed on modeling the growth and interactions of the various organisms that comprise the ecosystem, and the biogeochemistry arises as a consequence of these interactions. Implicit in this assumption is that changes in community structure will result in changes in biogeochemistry. The success of the modeling effort therefore depends on knowing who is there, what their growth characteristics are, and the interactions between the different organisms.

This organism-centric view is the approach currently most often used in ecosystem models, and if suitably parameterized has been quite successful in reproducing observations (Gentleman 2002). However, the weakness of this approach is that the model response is usually strongly dependent on the choice of parameter values, and as a result each model is essentially a case study of the site for which it was calibrated. Such models lose predictive power when faced with large-scale perturbations that result in shifts in the dominant organisms beyond the range of calibration. Yet this is precisely the situation for which models are most often needed.

The opposing view is a systems perspective, whereby energy, nutrients, and physical conditions determine the biogeochemistry. The exact species composition is unimportant, and species are interchangeable; only the metabolic function matters. The observation that many microbial ecosystems remain functionally and biogeochemically stable despite wide swings in species composition adds weight to this argument (Fernández et al. 1999, Graham et al. 2007, Benincà et al. 2008). Just as the ideal gas law can be used to calculate air pressure (the macrostate) without resorting to measuring the position and momenta of the molecules in a room (the microstates), the systems approach attempts to determine the flow of mass and energy through an ecosystem without specifying the individual organisms present or their interactions with each other. The advantage of this approach is that model results can be applied more generally and should in theory have more predictive power as they are not dependent upon the properties of a particular population of organisms. Despite these potential advantages, such models have been hampered because, aside from conservation of mass and energy, we have not yet discovered the fundamental laws or theories governing the organization of emergent ecosystems (if indeed such laws exist).

Recent research into non-equilibrium thermodynamics has suggested that the theory of maximum entropy production (MEP) may show promise as a principle of ecosystem organization (Kleidon et al. 2010, Vallino 2010, 2011). The application of thermodynamics to ecosystems began with Lotka (1922), who proposed that ecosystems will organize toward a state of maximum power. Schrödinger (1944) described ecosystems as dissipative structures, far from equilibrium systems that maintain low-entropy structures through the dissipation of an external energy gradient. Paltridge (1975) presented the first MEP model to describe a complex dissipative system by demonstrating that global heat flux between the tropics and poles operates in a state of MEP. Since then, MEP has been applied successfully to a wide range of complex systems such as the climatology of Mars and Titan (Lorenz et al. 2001), ocean circulation (Shimokawa \& Ozawa 2001), electric circuits (Christen 2006), crystal growth (Hill 1990), Earth systems (Kleidon 2009), and ecosystems (Swenson 1989). Recently, several quantitative biogeochemical models have been developed to examine key aspects of MEP in relation to ecosystems in a testable hypothesis-driven manner (Meysman \& Bruers 2007, 2010, Vallino 2010, 2011).

In this manuscript, we apply the ideas put forth by Vallino (2010) to a model that approximates nitrogen cycling in a coastal marine sediment. Our aim is to assess the ability of the MEP model formulation to predict switching between nitrogen cycling pro- 
cesses as a result of changes in environmental conditions, namely in the coupled rate of carbon and nitrogen delivery to the system. The marine sediment nitrogen cycle is well suited to the application of such a model because (1) all major nitrogen transformation processes are microbially mediated, (2) there are several respiratory pathways (denitrification, anammox, and DNRA) that compete for the same resources (electron donors and acceptors, and nutrients), and (3) the question is ecologically relevant, as the nitrogen cycle in many coastal environments is perturbed by anthropogenic nutrient loading, which can result in the degradation of water quality through eutrophication and the development of hypoxia.

\section{MEP THEORY}

Entropy, unfortunately, is often treated as a vague and qualitative concept, invoking statements of order and disorder. However, the original definition of entropy by Clausius (1850), the energy dissipated when converting internal energy into work, provides a concrete and quantitative thermodynamic definition. With this in mind, the entropy production rate is the rate at which a gradient of potential energy is dissipated through the conversion of energy from one form to another (Kleidon 2010a,b). A hurricane dissipates a gradient in thermal energy, a stream dissipates a gradient in gravitational potential energy as it flows down a mountainside, and a detritus-based ecosystem, such as a microbial community in a coastal sediment, dissipates a gradient in chemical potential energy through the oxidation (respiration) of organic matter.

Consider some reduced detrital carbon in Earth's oxidizing atmosphere. This organic matter is not in thermodynamic equilibrium with its surroundings. Its distance from equilibrium is expressed as the Gibbs free energy of reaction for its complete oxidation to carbon dioxide and water:

$$
\mathrm{CH}_{2} \mathrm{O}+\mathrm{O}_{2} \rightarrow \mathrm{CO}_{2}+\mathrm{H}_{2} \mathrm{O}
$$

If left to its own devices, this reaction will proceed, albeit at an extremely slow rate. This slow rate is a result of the large activation energy barrier that the reaction must overcome. If a flame is applied, the heat may provide enough energy to overcome this kinetic barrier and the reaction will proceed rapidly until all of the $\mathrm{CH}_{2} \mathrm{O}$ or $\mathrm{O}_{2}$ is consumed. This is known as the mode of 'steepest descent,' a state of maximum entropy production and the manner by which abiotic processes, such as fire, operate.
The reaction may also proceed rapidly if a catalyst that can sufficiently lower the activation energy barrier is added. Enzymes are the catalysts in biological systems. However, in a biological system, the catalyst must also by synthesized (grown) from the same materials involved in the reaction. The construction of a catalyst therefore decreases the amount of free energy that may be dissipated per extent of reaction, as some free energy must be allocated to anabolic (growth) processes.

An insufficient amount of catalyst can limit the reaction rate and consequently the rate of entropy production, while the synthesis of an overabundance of catalyst will lower the free energy dissipated by the reaction, also lowering entropy production. This tradeoff between catalyst building and free energy dissipation presents what appears to be a paradox. Since the construction of a catalyst will always decrease the instantaneous rate of entropy production, how do biological processes emerge when the background abiotic processes always adhere to the mode of steepest descent? How this can be reconciled with MEP theory is demonstrated in Fig. 1, which depicts a hypothetical potential energy surface for a system described by 2 components whose values are given along the $x$ - and $y$-axes. Each $(x, y)$ pair represents a possible macrostate of the system, and the corresponding point on the potential energy surface is the free energy associated with that state. The system can move through time from one macrostate to another, provided the change results in a decrease in the free energy of the system. The 2 arrows represent 2 possible trajectories of the system through time.

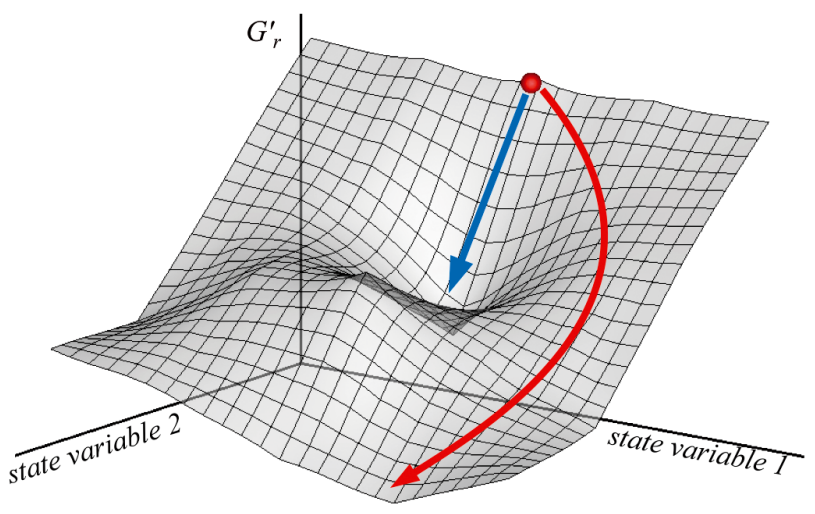

Fig. 1. Hypothetical potential energy surface $\left(G^{\prime}{ }_{r}\right)$. Each point on the potential energy surface corresponds to a possible macrostate of the system. The red dot is the initial state of the system and the colored arrows are 2 potential trajectories the system could follow with time. The blue arrow is the path of steepest descent, and the red arrow is the alternative path which ecosystems follow, if they have sufficient information 
The blue arrow represents the steepest descent pathway, whereby the system travels down the potential energy surface by the fastest allowable pathway. However, in this case it becomes stuck in a local potential energy minimum. If the free energy surface of Fig. 1 represents gravitational potential energy, and $x$ and $y$ are the spatial coordinates, an analogy can be drawn with a ball rolling down a hill. The ball will follow the steepest path down the hillside (steepest descent mode), but runs the risk of becoming trapped in a valley. The figure could also represent the simple 2-component reaction above, where the surface is chemical potential, and the blue trajectory represents the route of abiotic combustion.

If, however, the ball or ecosystem had some information about the potential energy surface, such that it could follow the red trajectory, then it could avoid the local energy minimum and ultimately dissipate a greater amount of energy than would be possible in the steepest descent case. Obviously, the ball has no means of storing or using this information and so will always follow the steepest descent case. An ecosystem, on the other hand, does have access to, and a means to use, such information.

Organisms store information in their genetic material. The information stored in the metagenome of an ecosystem has been acquired through evolution by natural selection, and can provide the information needed to exploit the red path (Fig. 1). Vallino (2010) hypothesized that it is this capacity to store and use information to exploit otherwise unavailable free energy dissipation pathways that separates biotic and abiotic systems. Even though the steepest descent pathway has the highest instantaneous entropy production rate, the average entropy production rate over time can be greater in biotic systems. Ecosystems will therefore maximize the average rate of entropy production over a characteristic timescale for which they have evolved to deal with. This application of MEP will form the central assumption for the model that we present and analyze below.

\section{MODEL FORMULATION}

To examine the potential of the MEP modeling approach, we present a simplified model of a detritusbased sediment microbial community where oxidized nitrogen species $\left(\mathrm{NO}_{3}{ }^{-}\right.$and $\left.\mathrm{NO}_{2}{ }^{-}\right)$serve as the primary electron acceptors.

Marine sediments host a detritus-based ecosystem, fueled by organic matter raining down on the sediments from productive surface waters. Electron accep- tors for respiratory processes are supplied mainly by diffusion across the sediment-water interface and often become limiting (Burdige 2006). This results in the successive utilization of terminal electron acceptors in a somewhat predictable fashion, $\mathrm{CO}_{2} \rightarrow \mathrm{NO}_{3}{ }^{-}$ $\rightarrow$ metal oxides $\rightarrow \mathrm{SO}_{4}{ }^{2-}$ ), the so called redox cascade (Froelich et al. 1979).

A typical depth profile of sediment porewater nitrogen species, along with oxygen, is shown in Fig. 2. In coastal sediments, $\mathrm{O}_{2}$ disappears within millimeters to centimeters of the sediment-water interface. In this narrow region of aerobic respiration, ammonium, released through remineralization, is oxidized through nitrification, and $\mathrm{NO}_{3}{ }^{-}$concentrations may increase with sediment depth. As oxygen becomes limiting, $\mathrm{NO}_{3}{ }^{-}$begins to replace $\mathrm{O}_{2}$ as the terminal electron acceptor for respiration, and $\mathrm{NO}_{3}^{-}$concentrations decrease. At deeper sediment depths, $\mathrm{NO}_{3}{ }^{-}$is depleted and other respiratory processes (metal oxide reduction, sulfate reduction, and methanogenesis) take over and ammonium concentrations increase. Here we model the layer of sediment immediate following oxygen depletion, where nitrate reduction takes place. This is indicated by the grey line in Fig. 2a.

The model domain is shown in Fig. $2 b$, where the nitrate reduction zone, labeled 'ecosystem,' is treated as a box within a larger box deemed the 'environment'. Both matter and energy can be exchanged between the environment and the ecosystem. Concentrations of chemical species are held constant in the environment but are modeled within the ecosystem. This admittedly simple representation of the spatial domain is used both to keep computation
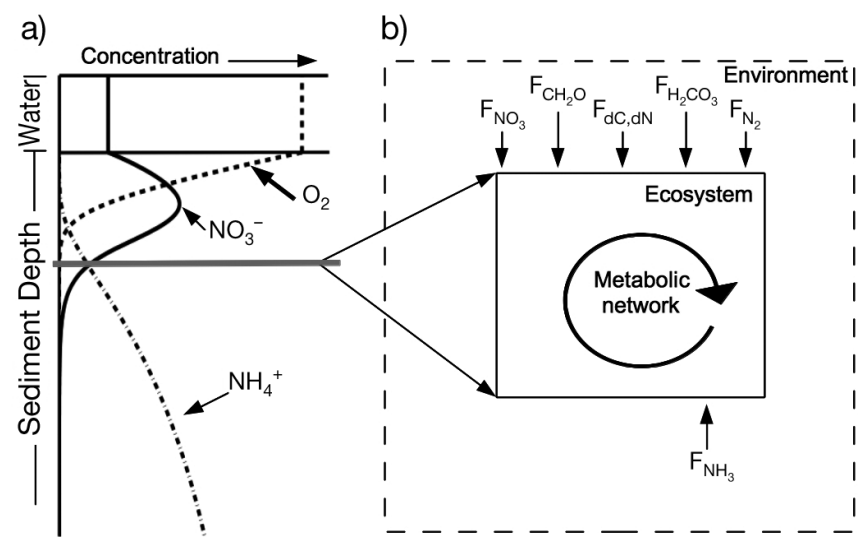

Fig. 2. (a) Typical depth profile of porewater $\mathrm{O}_{2}, \mathrm{NO}_{3}{ }^{-}$, and $\mathrm{NH}_{4}{ }^{+}$. The gray line represents a zone of nitrate reduction, and is the region considered in the maximum entropy production (MEP) model. (b) The idealized ecosystem model; arrows represent key fluxes of chemical species between the ecosystem (solid box) and the environment (dashed box) 
times reasonable and to simplify the interpretation of model results.

The model considers 8 chemical state variables, $\mathrm{NO}_{3}{ }^{-}, \mathrm{NO}_{2}{ }^{-}, \mathrm{NH}_{3}, \mathrm{~N}_{2}, \mathrm{CH}_{2} \mathrm{O}$, and $\mathrm{H}_{2} \mathrm{CO}_{3}$, plus 2 detritus pools; a carbon pool (dC) and a nitrogen pool (dN), and 5 biological structure variables $\left(\mathcal{S}_{i}\right)$ that catalyze reactions. $\mathrm{CH}_{2} \mathrm{O}$ represents small, easily metabolizable organic molecules, such as monomer sugars and short chain (C1 to $\mathrm{C} 3$ ) fatty acids, and serves as the substrate for microbial respiratory processes. The change in each state variable, $C_{k}$ is described by the following ordinary differential mass balance equation:

$$
\frac{\mathrm{d} C_{k}}{\mathrm{~d} t}=F_{C k}+\sum_{i} R_{i}
$$

where $F_{C k}$ is the input of $C_{k}$ from the environment to the ecosystem and the $R_{i}^{\prime}$ 's are the biological processes consuming $\left(R_{i}<0\right)$ or producing $\left(R_{i}>0\right)$ the state variable. The $F_{C k}$ 's are of the form described by Meysman \& Bruers (2007). For solutes, this is $F_{C k}=$ $\left(3 \varphi D_{k} / L^{2}\right)\left(C_{k}{ }^{0}-C_{k}\right)$ where $\varphi$ is the porosity, $D_{k}$ is the diffusion coefficient for the solute, $C_{k}{ }^{0}$ is the average concentration just above the sediment layer of interest, and $L$ is the width of this sediment layer. For particulates $\left(\mathrm{dC}, \mathrm{dN}\right.$, and $\left.\mathcal{G}_{i}\right) F_{C k}=\varphi w / L\left(C_{k}{ }^{0}-C_{k}\right)$, where $W$ is the sediment accumulation rate.

The microbial community inside the ecosystem box is represented by a metabolic network (Fig. 3) that depicts the major nitrogen transformation processes. For simplicity, only reactions involving carbon and nitrogen species are modeled; however, other metabolic reactions, such as sulfur biogeochemistry, can be readily incorporated into the framework. In reaction $R_{1}, \mathrm{NO}_{3}{ }^{-}$is reduced to $\mathrm{NO}_{2}{ }^{-}$with organic matter $\left(\mathrm{CH}_{2} \mathrm{O}\right)$ serving as the electron donor. The nitrite produced then serves as an electron acceptor for the following 3 competing processes: heterotrophic reduction of $\mathrm{NO}_{2}^{-}$to $\mathrm{N}_{2}\left(R_{2}\right)$; dissimilatory reduction of

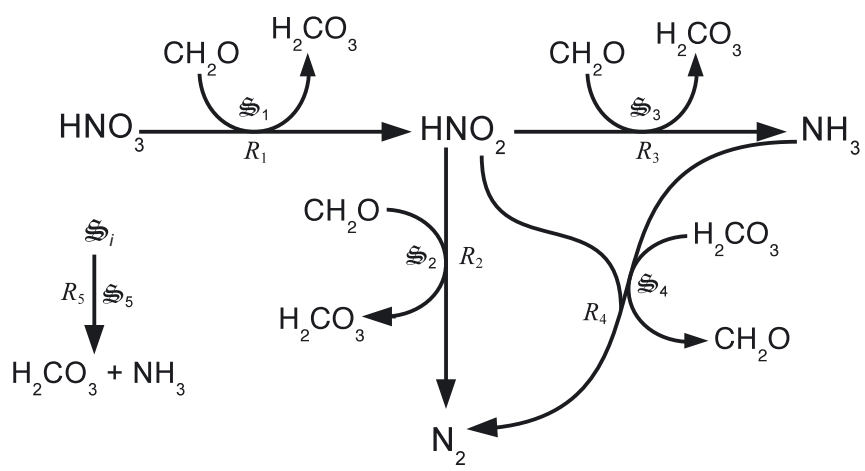

Fig. 3. Metabolic reaction network showing the major anoxic nitrogen cycling pathways that are represented in the maximum entropy production (MEP) nitrogen cycling model. ${ }_{i}$ 's are the 'biological structures' that catalyze their associated reactions nitrite to ammonium with organic matter again serving as the electron donor $\left(R_{3}\right)$; and anammox $\left(R_{4}\right)$, which uses nitrite to oxidize ammonia and produce $\mathrm{N}_{2}$. Reactions $R_{1}, R_{2}$, and $R_{3}$ are all heterotrophic processes with $\mathrm{CH}_{2} \mathrm{O}$ serving both as the electron donor and carbon source for growth. Reaction $R_{4}$ is chemolithoautotrophic and uses the energy obtained through the oxidation of $\mathrm{NH}_{3}$ to fix inorganic carbon.

The commonly referred to respiratory processes of denitrification (reduction of nitrate to dinitrogen) and DNRA can be recreated from the reaction network through linear combinations of $R_{1}, R_{2}$, and $R_{3}$. For example, the full DNRA process would consist of some portion of $R_{1}$ to provide a source of nitrate and $R_{3}$ to reduce this nitrite to ammonium. Because $R_{3}$ represents the terminal reduction in DNRA, it can be considered to be representative of the entire process, so DNRA will be used interchangeably with $R_{3}$ throughout the remainder of the text. Likewise, $R_{2}$ represents the terminal reduction in the denitrification process, so these 2 terms will also be used interchangeably.

$R_{5 \mathrm{a}}, R_{5 \mathrm{~b}}$, and $R_{5 \mathrm{c}}$ are reactions representing the turnover of biological structure. The turnover of microbial biomass is necessary for model closure and plays an important role in the ecosystem by (1) regenerating nutrients that would otherwise become limiting and (2) reallocating biological structure to reactions that dissipate free energy faster. Despite its importance, microbial mortality is difficult to characterize in the environment. Microbial biomass can turn over through predation by protists or predatory bacteria, viral lysis, or cell death. Quantifying the importance of each process is difficult, so representing biomass turnover in models remains a challenge. In our treatment, we represent higher trophic levels with a fifth biological structure pool, ${ }_{5}$, which catalyzes the oxidation of microbial biomass to carbon dioxide, and remineralization to $\mathrm{NH}_{3}$. In the model, this oxidation is carried out using any of the available electron acceptors, so $\mathcal{S}_{5}$ catalyzes 3 separate reactions, $R_{5 \mathrm{a}}$, $R_{5 \mathrm{~b}}$, and $R_{5 \mathrm{c}}$ which mimic the heterotrophic metabolic processes $R_{1}$ to $R_{3}$ (Table 1 ). Finally, detrital carbon $(\mathrm{dC})$ and nitrogen $(\mathrm{dN})$ are slowly converted into reactive forms, $\mathrm{CH}_{2} \mathrm{O}$ and $\mathrm{NH}_{3}$, by $R_{6}$ and $R_{7}$, according to simple first-order kinetics with respect to $\mathrm{dC}$ and heterotrophic biomass ( $\dot{S}_{1}, \dot{S}_{3}$, and $\dot{S}_{5}$ ).

Each metabolic process in Fig. 3 is treated as an autocatalytic reaction, whereby the biological structure that catalyzes the reaction, $\mathcal{S}_{i}$, is also produced by it. As an example, the reaction for nitrate reduction, $R_{1}$, with nitrate also serving as the nitrogen source for growth, is shown below: 
Table 1. Reactions and optimal control variables (OCVs) included in the maximum entropy production (MEP) microbial ecosystem model. Nitrate reduction and denitrification can use both oxidized and reduced nitrogen sources for growth. The stoichiometric coefficients of each reaction $\left(a_{11}, a_{12}, b_{11}, a_{3}\right.$, etc. ) vary with growth efficiency and are determined by mass and electron balances at each time step. DNRA: dissimilatory nitrate reduction to ammonium; $\varepsilon$ : growth efficiency; $\omega$ : weighting parameter for nutrient source; $\gamma$ : nitrogen:carbon ratio of biological structure

\begin{tabular}{|c|c|c|c|c|}
\hline Process & Reaction & Formula & $\begin{array}{l}\text { Biological } \\
\text { structure }\end{array}$ & $\mathrm{OCV}$ \\
\hline \multirow[t]{2}{*}{ Nitrate reduction } & $R_{11}$ & $\mathrm{CH}_{2} \mathrm{O}+a_{11} \mathrm{HNO}_{3} \stackrel{g_{1}}{\longrightarrow} \varepsilon_{1} \mathscr{g}_{1}+\left(1-\varepsilon_{1}\right) \mathrm{H}_{2} \mathrm{CO}_{3}+b_{11} \mathrm{HNO}_{2}+c_{11} \mathrm{H}_{2} \mathrm{O}$ & $\dot{S}_{1}$ & $\varepsilon_{1}, \omega_{1,1}$ \\
\hline & $R_{12}$ & $\mathrm{CH}_{2} \mathrm{O}+a_{12} \mathrm{HNO}_{3}+\gamma \mathrm{NH}_{3} \stackrel{g_{1}}{\longrightarrow} \varepsilon_{1}+\left(1-\varepsilon_{1}\right) \mathrm{H}_{2} \mathrm{CO}_{3}+b_{12} \mathrm{HNO}_{2}+c_{12} \mathrm{H}_{2} \mathrm{O}$ & $\dot{S}_{1}$ & $\varepsilon_{1}, 1-\omega_{1,1}$ \\
\hline \multirow[t]{2}{*}{ Denitrification } & $R_{21}$ & $\mathrm{CH}_{2} \mathrm{O}+a_{21} \mathrm{HNO}_{2} \stackrel{\mathscr{g}_{2}}{\longrightarrow} \varepsilon_{2} \mathscr{S}_{2}+\left(1-\varepsilon_{1}\right) \mathrm{H}_{2} \mathrm{CO}_{3}+b_{21} \mathrm{~N}_{2}+c_{21} \mathrm{H}_{2} \mathrm{O}$ & $g_{2}$ & $\varepsilon_{2}, \omega_{2,1}$ \\
\hline & $R_{22}$ & $\mathrm{CH}_{2} \mathrm{O}+a_{22} \mathrm{HNO}_{2}+\gamma \mathrm{NH}_{3} \stackrel{g_{2}}{\longrightarrow} \varepsilon_{2} \mathscr{S}_{2}+\left(1-\varepsilon_{1}\right) \mathrm{H}_{2} \mathrm{CO}_{3}+b_{22} \mathrm{~N}_{2}+c_{22} \mathrm{H}_{2} \mathrm{O}$ & $\dot{S}_{2}$ & $\varepsilon_{2}, 1-\omega_{2,1}$ \\
\hline DNRA & $R_{3}$ & $\mathrm{CH}_{2} \mathrm{O}+a_{3} \mathrm{HNO}_{3} \stackrel{\mathscr{g}_{3}}{\longrightarrow} \varepsilon_{3} \mathscr{S}_{3}+\left(1-\varepsilon_{1}\right) \mathrm{H}_{2} \mathrm{CO}_{3}+b_{3} \mathrm{NH}_{3}+c_{3} \mathrm{H}_{2} \mathrm{O}$ & $\dot{S}_{3}$ & $\varepsilon_{3}$ \\
\hline Anammox & $R_{4}$ & $a_{4} \mathrm{HNO}_{2}+\left(1-\varepsilon_{4}+\gamma \varepsilon_{4}\right) \mathrm{NH}_{3}+{ }_{4} \mathrm{H}_{2} \mathrm{CO}_{3} \stackrel{g_{4}}{\longrightarrow} \varepsilon_{4} \mathscr{S}_{4}+\left(1-\varepsilon_{1}\right) \mathrm{N}_{2}+b_{4} \mathrm{~N}_{2}+c_{4} \mathrm{H}_{2} \mathrm{O}$ & $\dot{S}_{4}$ & $\varepsilon_{4}$ \\
\hline \multirow{3}{*}{ Grazing } & $R_{5 a, j}$ & $\mathscr{S}_{j}+a_{51} \mathrm{HNO}_{3}+b_{51} \mathrm{H}_{2} \mathrm{O} \stackrel{g_{5}}{\longrightarrow} \varepsilon_{5} \mathscr{S}_{5}+\left(1-\varepsilon_{5}\right) \mathrm{H}_{2} \mathrm{CO}_{3}+c_{51} \mathrm{HNO}_{2}+\gamma \mathrm{NH}_{3}$ & $\dot{S}_{5}$ & $\varepsilon_{5}$ \\
\hline & $R_{5 b, j}$ & $\mathcal{S}_{j}+a_{52} \mathrm{HNO}_{2} \stackrel{\mathscr{g}_{5}}{\longrightarrow} \varepsilon_{5} \mathscr{S}_{5}+\left(1-\varepsilon_{5}\right) \mathrm{H}_{2} \mathrm{CO}_{3}+c_{52} \mathrm{~N}_{2}+c_{52} \mathrm{H}_{2} \mathrm{O}+\gamma \mathrm{NH}_{3}$ & $\dot{S}_{5}$ & $\varepsilon_{5}$ \\
\hline & $R_{5 c, j}$ & $\mathcal{S}_{j}+a_{53} \mathrm{HNO}_{2}+b_{53} \mathrm{H}_{2} \mathrm{O} \stackrel{\mathscr{g}_{5}}{\longrightarrow} \varepsilon_{5} \mathscr{g}_{5}+\left(1-\varepsilon_{5}\right) \mathrm{H}_{2} \mathrm{CO}_{3}+c_{53} \mathrm{NH}_{3}$ & $\dot{S}_{5}$ & $\varepsilon_{5}$ \\
\hline \multirow[t]{2}{*}{ Hydrolysis } & $R_{6}$ & $\mathrm{dC} \rightarrow \mathrm{CH}_{2} \mathrm{O}$ & - & - \\
\hline & $R_{7}$ & $\mathrm{dN} \rightarrow \mathrm{NH}_{3}$ & - & - \\
\hline
\end{tabular}

$$
\begin{gathered}
\mathrm{CH}_{2} \mathrm{O}+a_{11} \mathrm{HNO}_{3} \stackrel{\mathscr{g}_{1}}{\longrightarrow} \\
\varepsilon_{1} \mathscr{g}_{1}\left(1-\varepsilon_{1}\right) \mathrm{H}_{2} \mathrm{CO}_{3}+b_{11} \mathrm{HNO}_{2}+c_{11} \mathrm{H}_{2} \mathrm{O}
\end{gathered}
$$

where $\mathcal{G}_{1}$ is of the form $\mathrm{CH}_{\alpha} \mathrm{O}_{\beta} \mathrm{N} \gamma$. The reaction stoichiometric coefficients, $a_{i j}$, $b_{i j}$, and $c_{i j}$ depend upon the growth efficiency parameter $\varepsilon_{i}$ and are determined during the simulation from elemental balances on nitrogen, oxygen, and hydrogen. In a microbial community, the catalyst would be the actual enzymes carrying out the chemical reactions. In the model there is a level of abstraction, and ${ }_{1}$ is meant to represent all of the biomass in the community that is devoted to that particular metabolic pathway and could also include the cell machinery associated with transcription and translation, signaling pathways, transporters, and structural components. The growth efficiency parameter, $\varepsilon_{i}$, divides resources between the energy producing, catabolic pathway and the anabolic growth pathway. If $\varepsilon_{i}=0$, no resources are devoted to growth and only respiration occurs and the entropy production rate is high. When $\varepsilon_{i}=1$, all resources are allocated to growth, but there is no energy released to drive the reaction, and entropy production is minimal. The stoichiometry for each process is given in Table 1. For nitrate reduction, $R_{1}$ is split into 2 sub-reactions depending on the nitrogen source for growth. $R_{11}$ describes growth with nitrate and $R_{12}$ describes growth with ammonium. Switching between nitrogen sources is controlled by the weighting parameter $\omega_{1}$. The same is true for denitrification $\left(R_{2}\right)$. For DNRA $\left(R_{3}\right)$, nitrite is the sole nitrogen source for growth, and for anammox $\left(R_{4}\right)$, ammonium serves as the nitrogen source.
The kinetics of reactions $R_{1}$ to $R_{5}$ are given by a novel rate expression (Vallino 2011):

$$
r_{i, j}=v^{*}\left(1-\varepsilon_{i}^{2}\right) \varepsilon_{i}^{2} \dot{g}_{i} \prod_{k=1}^{n_{c}}\left(\frac{c_{k}}{c_{k}+\kappa^{*} \varepsilon_{i}^{4}}\right)^{\Lambda_{i, j, k}} \omega_{i, j} f_{G}\left(\Delta G_{r_{i}}\right)
$$

where $v^{*}$ and $\kappa^{*}$ are scaling constants for the maximum uptake $\left(v_{\max }\right)$ and half saturation $\left(k_{\mathrm{M}}\right)$ terms. The rational for these scaling constants is described shortly. The exponent $\Lambda_{i, j, k}$ is set to either 0 or 1 depending on the reaction stoichiometry (Table 1 ) for the $n_{c}$ concentration state variables, $C_{k}$. The weighting term $\omega_{i, j}$ determines how $\mathcal{B}_{i}$ is partitioned to its associated $j$ th sub-reactions. It is subjected to the constraint that all the $\omega_{i, j}$ for process $i$ must sum to one $\left(\sum \omega_{i, j}=1\right)$. For nitrate reduction and denitrification, which are both split into 2 sub-reactions depending upon the nitrogen source for growth (Table 1), $\omega_{i, 2}$ can be replaced by the relationship $\omega_{i, 2}=1-\omega_{i, 1}$. For the turnover of biological structure $\left(R_{5}\right) \omega_{5, j}=\dot{S}_{j} / \mathscr{S}_{\mathrm{T}}$, where

$$
\dot{S}_{\mathrm{T}}=\sum_{j} \dot{g}_{j}
$$

This implies that the $S_{j}$ 's are degraded indiscriminately, including cannibalism. Any number of subreactions can be similarly handled by introducing additional $\omega_{i, j}$ control variables.

The term $f_{G}\left(\Delta G^{\prime}{ }_{r}\right)$ is the thermodynamic driving force and limits the reaction rate as the free energy of reaction approaches 0 and ensures that the reaction will not proceed when the free energy is positive (Boudart 1976, Jin \& Bethke 2003). The thermodynamic driving force is described using the equation of LaRowe et al. (2012): 


$$
f_{G}\left(\Delta G_{r}^{\prime}\right)= \begin{cases}\left(\mathrm{e}^{\left(\Delta G_{r}^{\prime}+F \Delta \Psi\right) /(R T)}+1\right)^{-1} & \text { if } \Delta G_{r}^{\prime}<0 \\ 0 & \text { if } \Delta G_{r}^{\prime} \geq 0\end{cases}
$$

where $\Delta \Psi$ is the membrane potential in living microbial cells, and $F$ is Faraday's constant.

Eq. (4) is similar to the hyperbolic Monod growth equation with the modification that $v_{\max }$ the maximum uptake rate, and $k_{\mathrm{M}}$, the half saturation constant, are not independent of each other, but are both a function of the growth efficiency; $v_{\max }=v^{*} \times\left(1-\varepsilon^{2}\right) \varepsilon^{2}$ and $k_{\mathrm{M}}=\kappa^{*} \times \varepsilon^{4}$. This change allows the rate expression to approximate the effect of thermodynamic constraints upon the kinetics. As $\varepsilon \rightarrow 0$, the reaction rate drops to 0 to reflect reduced uptake at low growth efficiencies, while at $100 \%$ growth efficiency $(\varepsilon \rightarrow 1)$ the reaction rate again goes to 0 . This behavior reflects the fact that in order to proceed with $100 \%$ growth efficiency, a reaction must proceed reversibly and therefore infinitely slowly. This represents the classic tradeoff between speed and efficiency with which all thermodynamic systems must contend (Gnaiger 1990, Pfeiffer \& Bonhoeffer 2002).

The forms of the expressions for $v_{\max }$ and $k_{\mathrm{M}}$, namely the exponents on the growth efficiency terms, were chosen to recreate the family of curves in Fig. 4. This shows uptake rates predicted by Eq. (4) as a function of substrate concentration for several different growth efficiencies. At any given substrate concentration, the growth efficiency with the highest uptake rate dominates. At low substrate concentration, this is the low efficiency curve. This represents organisms that

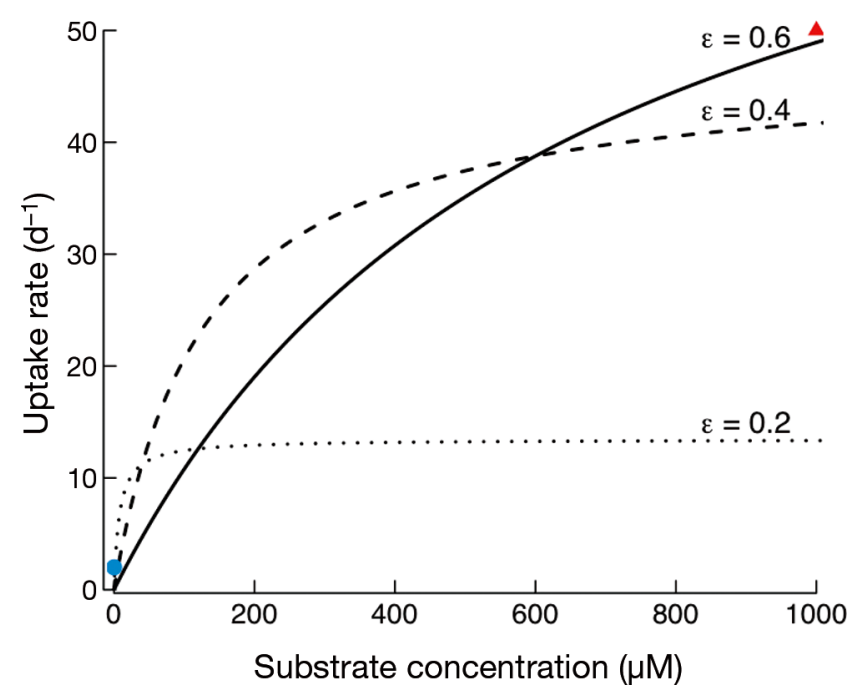

Fig. 4. Uptake rate as a function of substrate concentrations predicted by Eq. (4) for different growth efficiencies. For each case, the thermodynamic driving force, $f_{G}\left(\Delta G_{r}^{\prime}\right)$, is assumed to be 1. nutrient-limited conditions typical of oligotrophic oceans; $\boldsymbol{\Delta}$ : nutrient-replete conditions, such as in a laboratory culture have low $k_{\mathrm{M}}$ values and low maximum uptake rates, e.g. microbes that have adapted to oligotrophic environments (K-strategists). As the substrate concentration increases, the maximum uptake rates shift to curves with higher growth efficiencies. These high $\varepsilon$ curves represent opportunists or R-strategists. They can grow quickly due to a high specific uptake rate, but also have a high nutrient requirement (high $k_{\mathrm{M}}$ ) which limits the uptake rate at low concentrations.

The constants $v^{*}$ and $\kappa^{*}$ are universal scaling coefficients, whose values $\left(v^{*}=350 \mathrm{~d}^{-1}\right.$ and $\kappa^{*}=$ $5000 \mu \mathrm{M}$ ) were chosen such that Eq. (4) can span the entire range of conditions that support microbial growth, simply by adjusting $\varepsilon$. This ranges from oligotrophic conditions, such as observed in open ocean gyres, with substrate concentrations in the micromolar range, specific uptake rates around 1 to $2 \mathrm{~d}^{-1}$, and growth efficiencies of around 10 to $20 \%$ (del Giorgio \& Cole 1998, Carlson et al. 1999), to growth in nutrient-replete systems such as a laboratory culture with millimolar substrate concentrations, growth efficiencies of up to $60 \%$, and specific uptake rates of $50 \mathrm{~d}^{-1}$ (Bailey 1977, Lendenmann \& Egli 1998).

In the model, the effective composition of the microbial community is determined by the values of $\varepsilon_{1}$ to $\varepsilon_{5}$ that govern specific growth rates and determine the stoichiometry and kinetics of the reactions shown in Table 1. In natural ecosystems, each metabolic process would be carried out by a collection of microbial species each with different growth characteristics. Values of $\varepsilon_{i}$ therefore represent the average growth efficiency for a particular ecosystem function. In the language of statistical thermodynamics, it represents the observable ensemble average of the growth efficiencies of all individual species (microstates) carrying out the process of interest. Determining the correct state of the community and its associated kinetics is reduced to selecting the correct growth efficiencies $\left(\varepsilon_{i}\right)$ for each biological structure variable at any instance in time. This is accomplished using a thermodynamically constrained optimization procedure in which the $\varepsilon^{\prime}$ s and $\omega$ 's are treated as control variables and the entropy production rate is a goal function which is maximized over a characteristic timescale for which the community has evolved to deal with (Vallino 2010).

The rate of entropy production for each reaction in Table 1 is calculated according to:

$$
\dot{\sigma}_{i}=-\frac{r_{i} \Delta G_{r_{i}}^{\prime}}{T} V_{\text {sys }}
$$

where $\dot{\sigma}_{i}$ is the contribution of reaction $r_{i}$ to the internal entropy production of a system of volume $V_{\text {sys }} T$ is temperature in Kelvin, and $\Delta G_{r_{i}}^{\prime}$ is the Gibbs free 
energy of reaction. Gibbs free energy of reaction values are calculated according to the approach of Alberty $(2003,2006)$ for biological systems and account for dissociation equilibria between chemical species $\left(\mathrm{H}_{2} \mathrm{CO}_{3} \rightarrow \mathrm{H}^{+}+\mathrm{HCO}_{3}{ }^{-} ; \mathrm{NH}_{4}{ }^{+} \rightarrow \mathrm{H}^{+}+\mathrm{NH}_{3}\right.$ i etc. $)$ and activity coefficients. In addition to entropy production associated with reactions, entropy can also be produced as a result of exchange of matter between the environment and the ecosystem, but this entropy of mixing is small compared to the entropy produced in biogeochemical processes and can be neglected (Vallino 2011).

Using Eq. (6), the optimal control problem can be formulated as follows,

$$
\begin{aligned}
& \max \langle\dot{\sigma}\rangle=\frac{1}{\delta_{t}} \int_{t}^{t_{j}+\delta_{t}} \mathrm{e}^{-k_{w}\left(\tau-t_{j}\right)} \sum_{i} \dot{\sigma} \mathrm{d} \tau \\
& \begin{array}{ll}
\varepsilon_{i}, \omega_{i j} \\
\text { wrt: } \quad 0 \leq \varepsilon_{i} \leq 1 \\
\text { subject to: } & 0 \leq \omega_{i j} \leq 1
\end{array}
\end{aligned}
$$

This is a class of receding horizon optimal control problems (Chen \& Allgower 1998, Mayne et al. 2000). The growth efficiency, $\varepsilon_{i}$, and nitrogen uptake weighting terms, $\omega_{i j}$, are the optimal control variables (OCVs). By varying $\varepsilon_{i}$ between 0 and 1 , each pathway can be turned on and off and the portion of substrates dedicated to biomass growth changed. Likewise for $R_{1}$ (nitrate reduction) and $R_{2}$ (denitrification), adjusting $\omega_{i j}$ switches between uptake of reduced or oxidized forms of nitrogen for growth. The characteristic timescale over which the optimization is performed is given by $\delta_{t}$, and $\mathrm{e}^{-k_{w}\left(\tau-t_{j}\right)}$ is a weighting term which accounts for how much the optimization considers future events. If $k_{W}=0$, then the optimization weights all times within $\delta_{t}$ equally, while a larger value of $k_{W}$ places less emphasis on future events. The limit of $\delta_{t} \rightarrow 0$, would optimize for the instantaneous entropy production, corresponding to a system operating in steepest descent.

Eq. (7) was solved using a derivativefree optimization algorithm, BOBYQA (Powell 2010), and the integration of the system of ordinary differential equations (ODEs) was performed numerically using the high-precision integrator BiM (Brugnano \& Magherini 2004).

\section{SIMULATIONS AND RESULTS}

Figs. 5 to 7 show the results of a typical model simulation. The parameter values for the simulation were chosen to be reasonable approximations of values for a marine sediment (Table 2). Concentrations of nitrate $\left(\left[\mathrm{NO}_{3}{ }^{-}\right]_{0}\right)$ and carbon substrates $\left(\left[\mathrm{CH}_{2} \mathrm{O}\right]_{0}\right)$ in the overlying bulk phase were both set to $10 \mu \mathrm{M}$. In the model, $\mathrm{CH}_{2} \mathrm{O}$ represents the concentration of small easily metabolizable carbon molecules, such as monomer sugars or short chain (C1-C3) fatty acids. Concentrations of these molecules in sediment porewaters are not measured as often as nitrate, but are thought to be only a fraction (on the order of a few percent) of the total dissolved organic carbon pool. For example, acetate concentrations vary between $<1$ and $100 \mu \mathrm{M}$ in the upper layers of sediment (see Burdige 2002 for a review). The bulk phase value of $10 \mu \mathrm{m}$ for $\left[\mathrm{CH}_{2} \mathrm{O}\right]_{0}$ approximates a sediment layer receiving a low to mid-level of labile carbon input, such as might exist on the continental slope or lowproductivity area of the shelf. In addition to the flux of labile carbon and nitrate from above, there is also
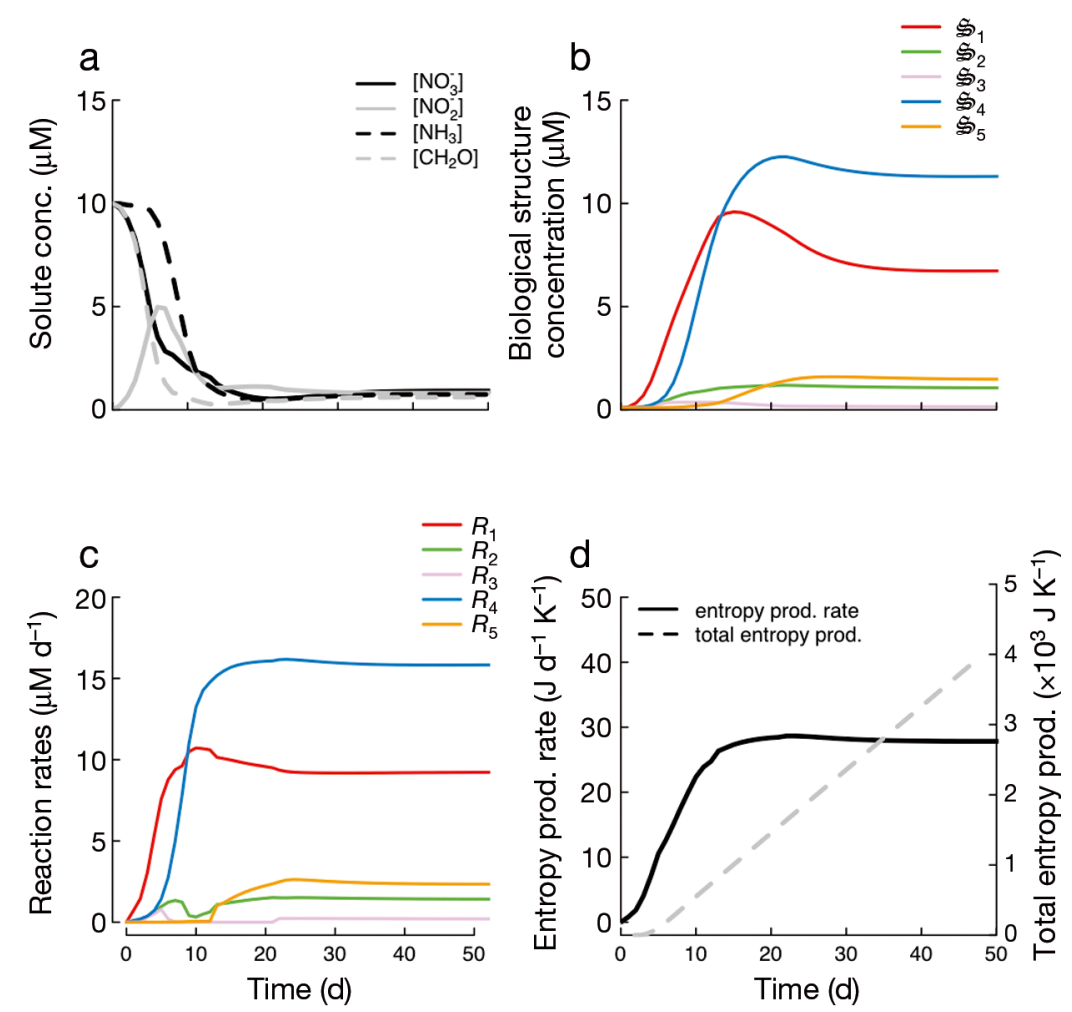

Fig. 5. Results from an example simulation. Solute concentrations in the surrounding environment were set to $\left[\mathrm{NO}_{3}{ }^{-}\right]_{0}=10 \mu \mathrm{M},\left[\mathrm{NO}_{2}{ }^{-}\right]_{0}=0 \mu \mathrm{M},\left[\mathrm{CH}_{2} \mathrm{O}\right]_{0}=$ $10 \mu \mathrm{M},\left[\mathrm{NH}_{3}\right]_{0}=10 \mu \mathrm{M}$. Concentrations for chemical variables at the start of the simulation were initialized to their bulk values. (a) Solute concentrations,

(b) biological structure concentrations, (c) reaction rates, and (d) entropy production rate (solid line) and cumulative entropy production (dashed line) 

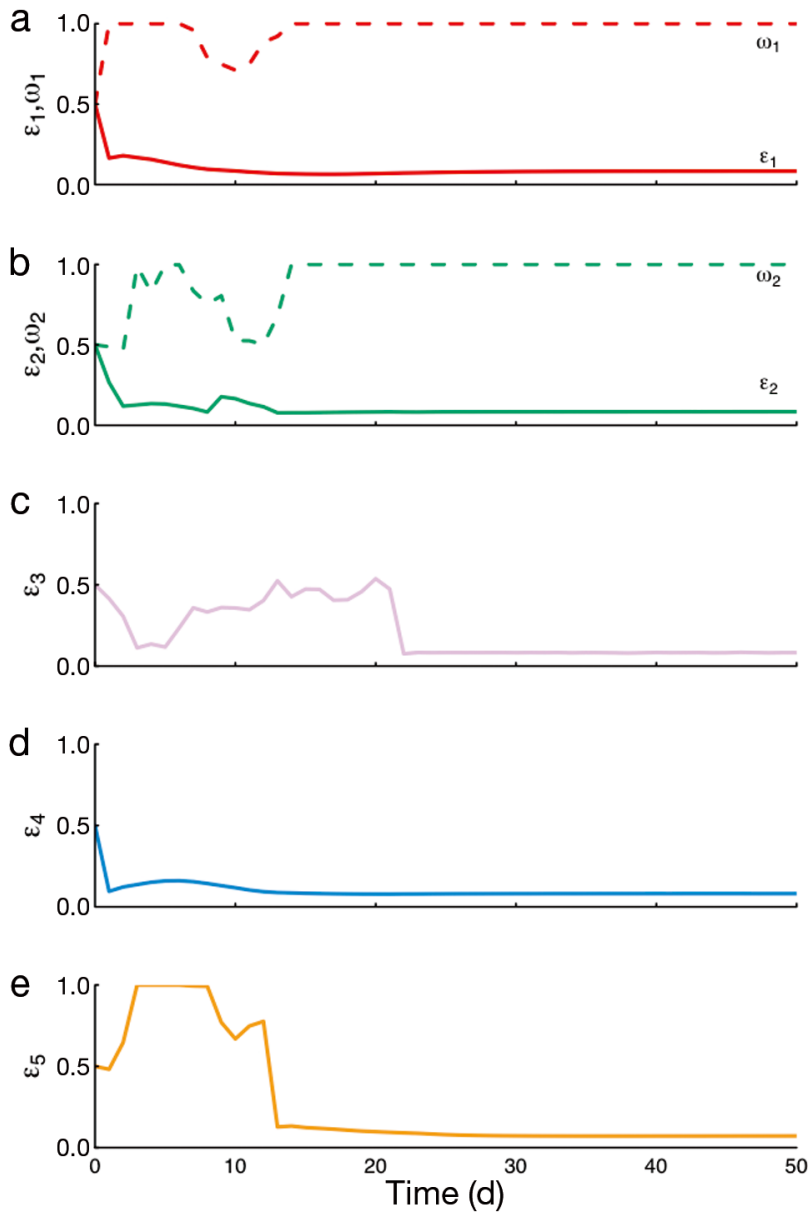

Fig. 6. Values for control variables during the example simulation. (a) Nitrate reduction $\left(R_{11}\right.$ and $\left.R_{12}\right), 2$ control variables, $\varepsilon_{1}$ and $\omega_{1}$. (b) Denitrification $\left(R_{21}\right.$ and $\left.R_{22}\right), 2$ control variables, $\varepsilon_{2}$ and $\omega_{2}$. (c) Dissimilatory nitrate reduction to ammonium (DNRA) $\left(R_{3}\right)$, control variable, $\varepsilon_{3}$. (d) Anammox $\left(R_{4}\right)$, control variable $\varepsilon_{4}$. (e) Grazing control variable $\varepsilon_{5}$
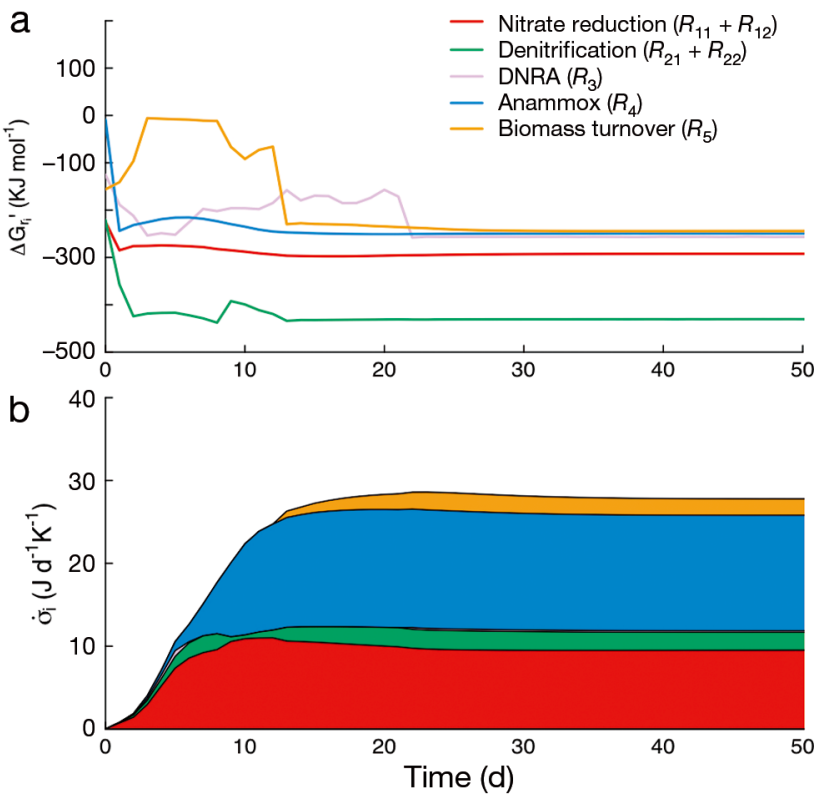

Fig. 7. (a) Free energy of reaction $\left(\Delta G^{\prime}{ }_{r}\right)$ for each modeled metabolic process through the course of the example simulation. The total free energy of each process is the sum of the free energy associated with the catabolic energy producing process and the anabolic growth process. The reactions used to calculate the free energies are given in Table 1. DNRA: dissimilatory nitrate reduction to ammonium. (b) Entropy production rate associated with each modeled metabolic process throughout the course of the simulation

a diffusive flux of ammonium across the lower model boundary. In the natural sediment environment, this ammonium flux would be the result of the remineralization of organic carbon deeper in the sediment, and reflects the fact that ammonium concentrations increase with depth in marine sediments.

Table 2. Parameters and boundary conditions used in example model simulation

\begin{tabular}{|c|c|c|c|c|}
\hline Parameter & Symbol & Units & Value & Source \\
\hline Optimization interval & $\delta_{t}$ & $\mathrm{~d}$ & 10 & - \\
\hline Optimization discounting parameter & $k_{W}$ & $d^{-1}$ & 1.0 & - \\
\hline Maximum specific rate parameter & $v^{*}$ & $d^{-1}$ & 350 & Vallino (2011) \\
\hline Substrate affinity parameter & $\kappa^{*}$ & $\mu \mathrm{M}$ & 5000 & Vallino (2011) \\
\hline Hydrogen in unit carbon formula for $\mathscr{B}_{i}$ & $\alpha$ & - & 1.4 & Dale et al. (2006) \\
\hline Oxygen in unit carbon formula for $\mathscr{g}_{i}$ & $\beta$ & - & 0.4 & Dale et al. (2006) \\
\hline Nitrogen in unit carbon formula for $\mathscr{S}_{i}$ & $\gamma$ & - & 0.2 & Dale et al. (2006) \\
\hline Detritus degradation rate constant & $k_{\mathrm{dC}, \mathrm{dN}}$ & $d^{-1}$ & 0.0027 & Boudreau (1996) \\
\hline Diffusion coefficient & $D$ & $\mathrm{~cm}^{2} \mathrm{~d}^{-1}$ & 1 & Vallino (2011) \\
\hline Membrane potential & $\Delta \Psi$ & $\mathrm{mV}$ & 120 & LaRowe et al. (2012) \\
\hline Sedimentation rate & $w$ & $\mathrm{~cm} \mathrm{yr}^{-1}$ & 0.3 & Meysman \& Bruers (2007) \\
\hline Porosity & $\varphi$ & - & 0.8 & - \\
\hline $\mathrm{pH}$ & - & - & 8.0 & - \\
\hline Salinity & $S$ & - & 35 & - \\
\hline Temperature & $T$ & $\mathrm{~K}$ & 283 & - \\
\hline Length scale & $L$ & $\mathrm{~cm}$ & 1 & - \\
\hline
\end{tabular}


Results are shown for $50 \mathrm{~d}$ of simulations. The model is initialized with a small amount of biological structure spread evenly amongst all biological structures $\left(\mathscr{g}_{i}=0.1 \mu \mathrm{M}\right)$, and solute concentrations are set equal to those of the bulk phase. During the early stages of the simulation, biological structure associated with nitrate reduction, $\mathcal{S}_{1}$, grows the quickest, as is evident in Fig. 5b after a few days of simulation. This results in a decrease in both $\mathrm{CH}_{2} \mathrm{O}$ and $\mathrm{NO}_{3}{ }^{-}$ and a spike in $\mathrm{NO}_{2}^{-}$(Fig. 5a) by Day 5. The increase in $\mathrm{NO}_{2}{ }^{-}$induces the synthesis of $\mathcal{S}_{2}, \mathcal{S}_{3}$, and $\mathcal{S}_{4}$, the biological structures responsible for catalyzing denitrification, anammox, and DNRA, respectively. This draws down $\mathrm{NO}_{2}{ }^{-}$levels. Initially all 3 structures are synthesized at similar rates, and this is reflected in similar reaction rates for all 3 processes (Fig. 5c). However, the system soon begins to allocate more resources to the autotrophic anammox processes and it dominates nitrogen cycling at steady state.

For the first $12 \mathrm{~d}$ of simulation, rates of the grazing reactions $\left(R_{5 \mathrm{a}}, R_{5 \mathrm{~b}}\right.$, and $R_{5 \mathrm{c}}$ ) and concentration of their catalyst, $\mathcal{S}_{5}$, are undetectable (Fig. 5b,c). However, near Day 12, these reactions switch on and $\mathcal{B}_{5}$ concentration increases (Fig. 5b). The primary role of the $R_{5}$ 's in the ecosystem is to turn over biological structure and liberate nutrients and carbon that are tied up in ${ }_{i}^{\prime}$ s. In the initial stages of the simulation, the environment is still nutrient replete as a result of the initial conditions and turnover is not needed for the resupply of nutrients. There is no net benefit to building the catalyst for $R_{5 \mathrm{a}}$ to $R_{5 \mathrm{c}}$. As the simulation continues, $\mathcal{B}_{i}$ concentrations increase, decreasing kinetic inhibition of $R_{5 \mathrm{a}, \mathrm{b}, \mathrm{c}}$ and the substrates for $R_{1}$ to $R_{4}$ are consumed and become limiting (Fig. 5), increasing the need for turnover of biological structure to resupply nutrients. The system responds by allocating resources to the synthesis of $\mathcal{S}_{5}$ and increasing the rate of the $R_{5}$ reactions. This 'spinning' of food webs produces considerable amounts of entropy when nutrients become limiting; otherwise entropy production would be limited by the influx of new nutrients across the system boundary.

Fig. 6 shows the values of the OCVs that control the synthesis of biological structure and correspondingly the state of the system. The solid lines are the growth efficiency parameters, $\varepsilon_{i}$, and the dashed lines for $R_{1}$ and $R_{2}$ give the value of the weighting parameter, $\omega_{i j \prime}$ specifying the nitrogen source for growth. At time $t=$ 0 , all OCVs were set equal to 0.5. At the start of the simulation, $\varepsilon_{1}$ drops rapidly to a value of 0.3 and then slowly decreases to a steady state value of 0.06 , giving a $v_{\max }=1.1 \mathrm{~d}^{-1}$ and $k_{\mathrm{M}}=0.05 \mu \mathrm{M}$. Such low values of $v_{\max }$ and $k_{\mathrm{M}}$ reflect growth in a nutrient-limited environment and are expected as $\mathrm{NO}_{3}{ }^{-}$concentrations during the model simulation drop to $<1 \mu \mathrm{M}$.

Values for $\varepsilon_{2}$ and $\varepsilon_{4}$ are similar throughout the simulation except for some subtle differences. Their values also drop initially, but then rise slightly between Days 1 and 5. This slight increase is the result of the accumulation of $\mathrm{NO}_{2}^{-}$and the ecosystem adjusting to take advantage of this increase in a nutrient by increasing the maximum uptake $\left(v_{\max }\right)$ term. In the environment, this shift in $\varepsilon$ would be the result of an increase in the faster-growing (more R-adapted) microbes with higher nutrient requirements. When $\mathrm{NO}_{2}{ }^{-}$begins to decrease, $\varepsilon_{2}$ and $\varepsilon_{4}$ decrease again, sacrificing a high $v_{\max }$ for a low $k_{\mathrm{M}}$, which in a population of microbes would result in a shift back to more K-strategists, adapted for oligotrophic growth. For the first $12 \mathrm{~d}$ of simulation, the grazing reactions, $R_{5}$ 's, are turned off. This is accomplished by setting $\varepsilon_{5}$ to 1.0. As biological structure accumulates and nutrients decease, the need for grazing increases and the value of $\varepsilon_{5}$ decreases, switching on $R_{5 \mathrm{a}}, R_{5 \mathrm{~b}}$, and $R_{5 \mathrm{c}}$.

A key aspect of our model is the premise that ecosystems maximize entropy production over a characteristic timescale, rather than the steepest descent mode of abiotic systems. In the optimization procedure, the consideration of future conditions is controlled with 2 parameters, the length of the optimization interval $\left(\delta_{t}\right)$ and the weighting term $k_{w}$. A shorter length of the optimization interval or a higher value of $k_{w}$ places more emphasis on present rather than future conditions and can approximate steepest descent behavior. To examine the influence of timescale, the sensitivity of the model to these parameters was examined with a series of simulations shown in Table 3.

From these results it can be seen that increasing the length of the optimization interval $\left(\delta_{t}\right)$ or the weighting of future conditions $\left(k_{w}\right)$ increases the rate of entropy production and the amount of biomass at

Table 3. Entropy production rate and biomass concentrations for different values of the optimal control variables, $\delta_{t}$ and $k_{W}$. Other parameters were set to the values given in Table 2

\begin{tabular}{|lcccc|}
\hline $\begin{array}{l}\delta_{t} \\
(\mathrm{~d})\end{array}$ & $\begin{array}{c}k_{W} \\
\left(\mathrm{~d}^{-1}\right)\end{array}$ & $\begin{array}{c}\dot{\sigma} \\
\left(\mathrm{kJ} \mathrm{mol}^{-1} \mathrm{~K}^{-1} \mathrm{~d}^{-1}\right)\end{array}$ & $\begin{array}{c}\sigma \\
\left(\mathrm{kJ} \mathrm{mol}^{-1} \mathrm{~K}^{-1}\right)\end{array}$ & $\begin{array}{c}\mathcal{S}_{\mathrm{T}}=\sum_{j} \dot{g}_{j} \\
(\mu \mathrm{M})\end{array}$ \\
\hline 0.1 & 46 & 12.8 & 1270 & 4.4 \\
0.1 & 23 & 13.1 & 1280 & 4.5 \\
0.1 & 0.0 & 13.1 & 1290 & 4.5 \\
1.0 & 0.0 & 24.0 & 2210 & 12.7 \\
5.0 & 0.0 & 27.0 & 2520 & 17.7 \\
10.0 & 0.0 & 28.7 & 2590 & 20.7 \\
\hline
\end{tabular}


steady state. At the shortest timescales $\left(\delta_{t}=0.1 \mathrm{~d}\right.$ and $k_{W}=0.01 \mathrm{~d}^{-1}$ ) the model chooses not to allocate resources to the synthesis of biological structure because doing so limits the free energy dissipated by pure catabolic processes. This is approaching a steepest descent mode of operation. The longer optimization intervals, however, do consider the future benefits of building catalyst. Over time, this results in a greater concentration of catalyst, higher reaction rates, generating more entropy production (column 3 of Table 3), and a faster cycling of the food web. The increase in entropy production with increasing optimization interval is most pronounced at shorter timescales (short $\delta_{t}$ or high $k_{w}$ ) and levels off at the longer optimization intervals (5 and $10 \mathrm{~d}$ ). For this reason, we chose $10 \mathrm{~d}$ as the optimization interval for all other simulations we discuss.

Fig. 8 explores the sensitivity of the model to carbon and nitrate delivery rates to the sediment and the effect this will have on the dominant nitrate reducing pathway. The rates of respiratory nitrate reduction occurring by denitrification $\left(R_{2}\right)$, DNRA $\left(R_{3}\right)$, and anammox $\left(R_{4}\right)$ are shown for a series of simulations where the ratio of $\mathrm{NO}_{3}{ }^{-}$to $\mathrm{CH}_{2} \mathrm{O}$ in the bulk layer was varied between 0.5 and 5. Adjusting the concen-

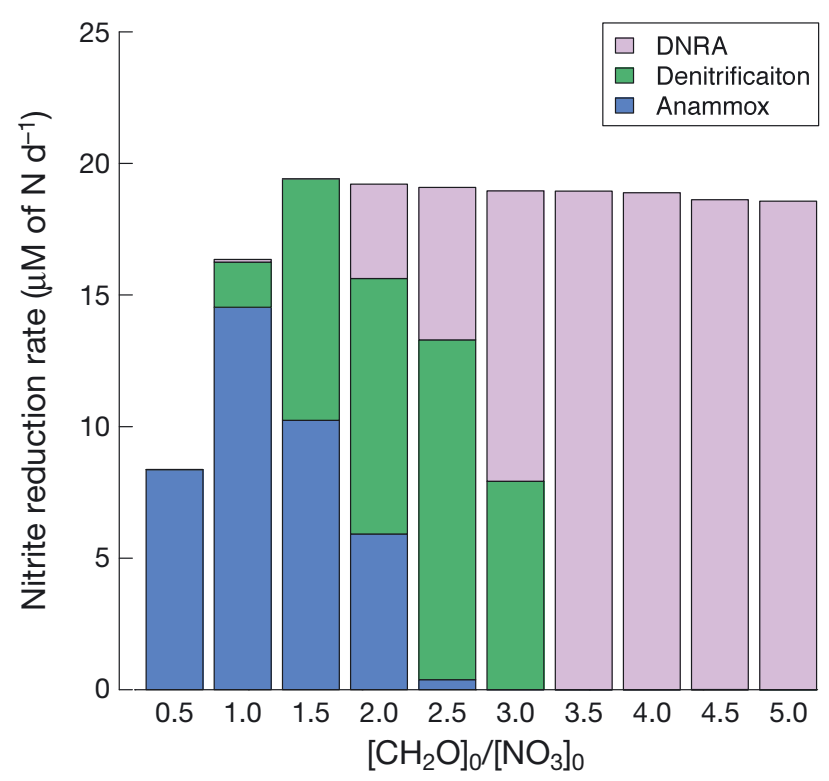

Fig. 8. Rates of nitrate reduction for each metabolic pathway (denitrification, anammox, and dissimilatory nitrate reduction to ammonium, DNRA) from simulations with different carbon and nitrate delivery rates. For each simulation, the carbon and nitrate delivery rate was adjusted by changing the concentrations of the bulk phase. $\left[\mathrm{NO}_{3}{ }^{-}\right]_{0}=10 \mu \mathrm{M}$ and $\left[\mathrm{CH}_{2} \mathrm{O}\right]_{0}$ was adjusted to give a series of carbon:nitrate ratios in the bulk phase between 0.5 and 5 . A diffusive flux exchange of ammonium with a deeper bulk phase of $\left[\mathrm{NH}_{3}{ }^{-}\right]_{0}=$ $10 \mu \mathrm{M}$ was also included trations of $\mathrm{NO}_{3}{ }^{-}$and $\mathrm{CH}_{2} \mathrm{O}$ in the bulk phase adjusts the flux of each to the model domain by approximately the same amount since the diffusive flux is directly proportional to the concentrations in the bulk phase. In each of these simulations, $\left[\mathrm{NO}_{3}{ }^{-}\right]_{0}$ was set to $10 \mu \mathrm{M}$ and $\left[\mathrm{CH}_{2} \mathrm{O}\right]_{0}$ was varied between 5 and $50 \mu \mathrm{M}$. This creates a series of simulations whereby the ratio of carbon to nitrate delivery to the region of interest varies from 0.5 to 5 . Also, as in the previous simulation, the lower model boundary was in contact with an $\mathrm{NH}_{3}$ bulk phase of $10 \mu \mathrm{M}$ to allow a flux of ammonium from below.

The results of these simulations show that the ratio of metabolizable carbon (electron donor) flux to $\mathrm{NO}_{3}{ }^{-}$ (electron acceptor and nutrients) has a significant influence on the dominant respiratory pathway. At low $\mathrm{CH}_{2} \mathrm{O}: \mathrm{NO}_{3}{ }^{-}$ratios, the system is carbon limited and the autotrophic anammox process dominates. All of the available carbon is allocated to reducing nitrate to nitrite, the nitrite can then be further reduced by anammox $\left(R_{4}\right)$ to $\mathrm{N}_{2}$ which does not require any additional $\mathrm{CH}_{2} \mathrm{O}$. Anammox also fixes additional carbon from $\mathrm{H}_{2} \mathrm{CO}_{3}$, which can then be used to further reduce more of the excess nitrate to nitrite.

As the ratio of $\left[\mathrm{CH}_{2} \mathrm{O}\right]_{0} /\left[\mathrm{NO}_{3}{ }^{-}\right]_{0}$ in the environment is increased, all of the carbon no longer needs to be allocated to $R_{1}$, and some of the carbon can be used to further reduce nitrite either by denitrification or DNRA. At intermediate $\mathrm{CH}_{2} \mathrm{O}: \mathrm{NO}_{3}{ }^{-}$ratios, denitrification becomes the most significant process, as it has the greatest free energy yield per mole of carbon (Fig. 7). However, at the highest carbon inputs, DNRA replaces both anammox and denitrification completely as the sole nitrite reduction pathway despite the free energy yield per mole of carbon being lower than that of denitrification. At these high ratios, it is the electron acceptor (nitrite) rather than carbon that is limiting. DNRA reduces nitrite to a lower oxidation state than denitrification, 6 electrons transferred per mole of nitrogen reduced for DNRA compared to only 3 for denitrification. The result is that DNRA makes more efficient use of the available electron acceptor and over time results in more carbon oxidized and more entropy produced than would be accomplished through denitrification, despite the greater free energy of denitrification per extent of reaction.

\section{DISCUSSION}

We have presented a model that adopts a systems view of the biogeochemistry of microbial ecosystems. The model was set up to simulate the nitrate reduc- 
ing microbial community in marine sediments and used to predict the dominant nitrate reducing pathway as a result of changes in the supply of carbon and nitrogen. In our approach, the ecosystem function is governed by the supply of nutrients and potential energy, rather than the particular species of microbes. In this view, two environments that have similar energy and nutrient regimes may develop a different community composition in terms of the particular types of species present, but functionally, the processing of matter and energy in the two ecosystems would be indistinguishable.

In the model, microbial biomass is represented as different pools of biological structure, with each pool responsible for catalyzing a specific function or metabolic process. While it may be tempting to assign each pool of biological structure to a particular group or class of microbe, this is only a loose association. In the model, each $\dot{S}_{i}$ represents the portion of biomass in the community that is devoted to a specific process, but not how this biomass is packaged into individual organisms. Each type of $\mathcal{S}_{i}$ could be spread over several different types of organisms, or a single species could contain biological structure for catalyzing multiple processes. For example, most denitrifiers can carry out nitrate reduction all the way to $\mathrm{N}_{2}$ and so would contain biological structure responsible for both nitrate reduction $\left(\mathcal{G}_{1}\right)$ and denitrification $\left(g_{2}\right)$. Likewise, anammox bacteria have shown the potential to carry out DNRA (Güven et al. 2005) and so could contain both $\mathcal{S}_{3}$ (DNRA) and $\mathscr{S}_{4}$ (anammox). This is similar to how the emerging field of metagenomics currently provides information on the presence of specific functional genes in an environment, but not necessarily which organisms the genes belong to (Konopka 2009). However, recently Iverson et al. (2012) demonstrated a method of assembling complete genomes from metagenomic data, so the ability to link functional genes to specific organisms may soon be possible. As metagenomic techniques mature and provide greater insight into the functional potential of microbial communities and metatranscriptomics identifies the active pathways (Simon \& Daniel 2011), models such as ours will be well suited to compare with these data. Each reaction in the model could be associated with specific groups of functional genes that could serve as markers for the presence or activity in the environment of the pathways predicted by the model.

The model uses MEP theory to predict the active pathways in the community metabolic network (Fig. 3). MEP therefore provides a direction governing the emergent properties of the microbial ecosys- tem. The MEP view of an ecosystem predicts that complex biological systems will emerge and persist if they increase the rate of time-averaged entropy production and exploit lower free energy states that would otherwise be unavailable with an abiotic steepest descent mode, i.e. if they follow the red as opposed to blue path in Fig. 1.

The aspect of timescale is a key feature of our model. Temporal strategies are seldom included in biogeochemical or ecosystem models despite numerous examples in biological systems. Trees storing energy produced during the growing season for the upcoming winter is an obvious example. At the microbial scale, luxury uptake and storage of nutrients, periods of dormancy, or spore formation are strategies that are incompatible with a steepest descent mode of living. Our model is an attempt to represent temporal strategies in a biogeochemical model.

As Table 3 clearly shows, increasing the optimization interval increases the rate of entropy production and free energy dissipation of the system. However, the question of the correct timescale over which to perform the optimization remains. The temporal strategies that allow a community of organisms to operate away from the mode of steepest descent (following the red path in Fig. 1) are the result of information stored in the genomes of the ecosystem's components (the individual species that make up the community). This information has accumulated through the trial and error process of evolution and therefore it is likely that the timescale of optimization is linked to the timescale over which DNA is passed from one generation to another. The chosen $10 \mathrm{~d}$ timescale for the simulations presented here is consistent with this, as doubling times in nutrient-limited environments are often shown to be on the order of days (del Giorgio \& Cole 1998, Carlson et al. 1999). Developing a more rigorous connection between the timescale of optimization and the transmission of information is a necessary direction for future research, but beyond the scope of this work.

An often held view in microbial ecology and biogeochemistry, and in particular sediment biogeochemistry, is that the mode of metabolism with the largest free energy yield will dominate and outcompete less thermodynamically favored processes. However, this is seldom backed up with thermodynamic calculations or a model of how this competition occurs (Bethke et al. 2011). While there are many situations where this generally holds true on a coarse scale, such as the 'redox cascade' in marine sediments (Froelich et al. 1979), there are numerous exceptions to this rule. There is often overlap between 
zones in the redox cascade, such as evidence of denitrification under aerobic conditions (Gao et al. 2010) or the co-occurrence of nitrate reduction and manganese reduction at the same sediment depth (Burdige 1993). Similarly, the question arises as to how chemoautotrophic processes can compete with more energetically favored heterotrophic processes for the same electron acceptors (i.e. $\mathrm{O}_{2}$ or $\mathrm{NO}_{3}{ }^{-}$). Our model simulations provide some insight into this and provide a different interpretation of the role thermodynamics plays in microbial competition.

Kleidon (2010b) referred to entropy as the dissipation of a driving energy gradient. Therefore, maximizing the rate of entropy production for an ecosystem means maximizing the highest sustainable energy flow through the system for a given temperature, with a net productivity of 0 at steady state. If the temperature is constant, MEP is equivalent to maximizing the rate (energy per unit time) of free energy dissipation. Those processes that dominate will be those that result in the greatest free energy flow through the system. This is a function of both the free energy of reaction and the rate at which the reaction can occur (Eq. 6). This reflects the influence of both thermodynamic and kinetic constraints upon the free energy available to microbes. In many cases, this view would result in only subtle differences, as the free energy of reaction is still an important term in the entropy production rate. It could, however, account for apparent violations in the redox cascade and cases of mutualism between modes of metabolism that might at first appear to be in direct competition (Bethke et al. 2011). Such instances would occur if the presence of both processes in some way increases the rate of free energy dissipation over that of a single process winning out.

This is demonstrated in our sample simulation. Fig. 7 a shows the $\Delta G^{\prime}$ r of each reaction throughout the simulations and accounts for changes in free energy associated with changes in the activities of the reactants and products, and changes in the relative importance of the catabolic and anabolic portions of the reaction. Denitrification has the most negative $\Delta G^{\prime}{ }_{\mathrm{r}}$ and therefore is the most thermodynamically favorable process, but anammox $\left(R_{4}\right)$ is the dominant end process for nitrate reduction and is responsible for most of the entropy production (Fig. 7b). The reason is that denitrification $\left(R_{2}\right)$ is limited by the availability of labile organic matter whereas the anammox rate is not, so a higher rate of energy flow is possible through this pathway, despite not being as thermodynamically favored. As a consequence, $R_{4}$ can outcompete $R_{2}$ for available nitrite.
To evaluate the modeling approach, we performed a series of model simulations with differing carbon and nitrate inputs. The model predicted switches in the dominant nitrate reduction pathway that are consistent with the current understanding of controls on nitrogen cycling in the environment (Burgin \& Hamilton 2007). At low inputs of organic carbon relative to nitrate, the autotrophic anammox process is predicted to dominate nitrate reduction with a switch to heterotrophic denitrification as the ratio of $\mathrm{CH}_{2} \mathrm{O}$ to $\mathrm{NO}_{3}{ }^{-}$ input rises. This is consistent with observational evidence that anammox is often important in deeper marine sediments (Thamdrup \& Dalsgaard 2002, Dalsgaard et al. 2005). Such sediments typically have lower inputs of labile organic matter and are overlain by nitrate-rich bottom waters. In coastal and estuarine environments, inputs of labile organic matter are higher and anammox has been shown to account for only 0 to $20 \%$ of $\mathrm{N}_{2}$ production. Engström et al. (2005) showed an inverse correlation between anammox and chlorophyll $a$, a proxy for sediment carbon reactivity, and Rysgaard et al. (2004) showed a positive correlation between $\mathrm{NO}_{3}{ }^{-}$levels and anammox rate.

At a higher ratio of $\mathrm{CH}_{2} \mathrm{O}$ to $\mathrm{NO}_{3}{ }^{-}$input, there is a switch to denitrification $\left(R_{2}\right)$ and then finally to DNRA $\left(R_{3}\right)$ as the dominant pathway. This corresponds to a switch from a carbon-limited to a nitrogen-limited environment. Although DNRA has not been as well studied as denitrification in sediment environments, in a review of nitrate removal pathways, Burgin \& Hamilton (2007) suggested that DNRA is the dominant pathway when levels of organic carbon input are high and nitrate levels are low. Results such as these suggest that the role of DNRA in coastal environments needs to be investigated in more detail. Both denitrification and anammox produce $\mathrm{N}_{2}$ as their end product, which is for most organisms biologically unavailable and a sink for reactive nitrogen in the environment, ameliorating the effects of nutrient loading in coastal environments. DNRA produces ammonium which remains bioavailable and consequently enhances the recycling of reactive nitrogen between coastal sediments and surface waters. This can exacerbate the effects of nutrient loading and serve as a positive feedback on eutrophication.

One aspect of Fig. 8 is that it may underestimate the importance of denitrification relative to the 2 other nitrate removal pathways. Burgin \& Hamilton (2007) stated that, while the importance of denitrification in many environments has been overestimated, it nevertheless remains the dominant form of nitrate reduction in most environments including marine sediments. The most likely reason for this 
under-representation of $R_{2}$ in the model simulations is that the kinetics of each process are treated equally. Each process has the same values for the scaling constants $v^{*}$ and $\kappa^{*}$. However, not all reactions are equal, some will have higher activation energy and as a result could be harder to catalyze requiring the synthesis of a greater amount of $\mathcal{B}_{i}$. The result is that some processes would have intrinsically slower growth rates than others.

Anammox bacteria, for example, have exceedingly slow growth rates, with doubling times of up to $10 \mathrm{~d}$ (Strous et al. 1999). This growth rate may be due in part to autotrophic growth and the high energy for carbon fixation. Another hypothesis is that slow growth could be tied to the synthesis of a particular type of ladderane phospholipids, which contain notoriously difficult to synthesize butane ring structures and are unique to anammox bacteria (van Niftrik et al. 2004). These ladderanes are needed in the construction of the anammoxosome. This vacuole, present in all anammox bacteria, is thought to be necessary to the respiratory processes by protecting the microbes from highly reactive metabolites, such as hydrazine, that are produced as intermediates in the anaerobic oxidation of ammonium (Strous et al. 2006). If in fact this means that anammox is an intrinsically more difficult process to catalyze than denitrification, then it is possible that the model, as it is presented in Fig. 6, is overemphasizing the importance of anammox at the expense of denitrification. This could be adjusted for by tuning the values of $v^{*}$ and $\kappa^{*}$ for each reaction. However, this was not the primary goal of our simulations. Instead, we wished to specify as few empirical parameters as possible and to develop a model that could still produce biologically meaningful behavior with as little 'tuning' as possible.

The advantage of the approach presented here is the ability of the model to predict switching between modes of metabolism. Such switching could not be captured by traditional kinetic models without reparameterization of the kinetic growth parameters or introducing conditional statements. However, in our model, the optimization procedure adjusts the $k_{\mathrm{M}}$ and $v_{\max }$ dynamically and so this switching behavior becomes a model prediction rather than a 'tuned' response. As is described above, the predicted switching is consistent with the current understanding of the marine sediment nitrogen cycle, suggesting that this approach could improve the predictive capacity of current biogeochemical models. However, a rigorous comparison of the model against data is still needed. Unfortunately, such an environmental dataset is difficult to collect. Ideally, to test the model, one would compare a switch in biogeochemistry predicted by the model with an observed shift in the field. However, for logistical reasons sediment biogeochemistry studies seldom have the temporal resolution to capture such dynamic behavior; often cores are collected at just a single or a few time points. An alternative test could be conducted through the use of meso- or microcosm experiments. In such an experiment, a sediment microbial community could be stabilized under a tightly controlled set of conditions approximating the natural environment. A large environmental perturbation would then be introduced and the community allowed to adjust. Ideally, such an experiment would also be performed in conjunction with metagenomic and metatranscriptomic measurements, to assess the metabolic capacity of the active microbial community before and after the perturbation. Such model validation is the next step toward incorporating this modeling framework into larger-scale spatial reactive-transport biogeochemical models.

\section{CONCLUSIONS}

We have used a metabolic network and the principle of maximum entropy production to develop a model for nitrate reduction in marine sediments. This model selects the active biogeochemical pathway by allocating biological material (catalyst) to processes that increase the internal entropy production of the system. We adjusted the level of organic carbon and nitrate during simulations to investigate the role of coupled carbon and nitrate input on the model response. From this we observed that competition for electron donors (organic carbon) and acceptors (nitrate and nitrite) has a major influence on the model response, with anammox dominating in carbon (electron donor) limited simulations, and heterotrophic denitrification and DNRA dominating in electron acceptor (nitrate) limited environments. This response is in agreement with observations of active nitrate reduction pathways in the environment.

The ability of the model to generate biologically meaningful results with a minimum of kinetic parameterization suggests that the approach may be promising for modeling microbial dynamics and the resulting biogeochemistry in systems where accurately measuring kinetic growth constants is difficult or when predicting the community response to largescale environmental perturbations. This approach also provides estimates of functional potential and activity that can be compared to metagenomic and metatranscriptomic data, respectively. 
Acknowledgements. We thank our colleagues A. Giblin, J. Rich, and J. Tucker for their helpful discussions, as well as A. Dale and an anonymous reviewer for their insightful comments. This research was supported by NSF grant OCE0852263 (C.K.A., J.J.V.), NSF grants OCE-1238212, EF0928742 (J.J.V.), and by the Gordon and Betty Moore Foundation grant GBMF3297 (C.K.A.).

\section{LITERATURE CITED}

Alberty RA (2003) Thermodynamics of biochemical reactions. Wiley \& Sons, Hoboken, NJ

Alberty RA (2006) Biochemical thermodynamics: applications of Mathematica. Wiley \& Sons, Hoboken, NJ

Bailey J (1977) Biochemical engineering fundamentals. McGraw-Hill, New York, NY

> Benincà E, Huisman J, Heerkloss R, Johnk KD and others (2008) Chaos in a long-term experiment with a plankton community. Nature 451:822-825

Bethke CM, Sanford RA, Kirk MF, Jin Q, Flynn TM (2011) The thermodynamic ladder in geomicrobiology. Am J Sci 311:183-210

Boudart M (1976) Consistency between kinetics and thermodynamics. J Phys Chem 80:2869-2870

Boudreau BP (1996) A method-of-lines code for carbon and nutrient diagenesis in aquatic sediments. Comput Geosci 22:479-496

Brugnano L, Magherini C (2004) The BiM code for the numerical solution of ODEs. J Comput Appl Math 164: 145-158

Burdige DJ (1993) The biogeochemistry of manganese and iron reduction in marine sediments. Earth Sci Rev 35: 249-284

Burdige DJ (2002) Sediment pore waters. In: Hansell DA, Carlson CD (eds) Biochemistry of marine dissolved organic matter. Academic Press, San Diego, CA, p 611-663

Burdige DJ (2006) Geochemistry of marine sediments. Princeton University Press, Princeton, NJ

Burgin AJ, Hamilton SK (2007) Have we overemphasized the role of denitrification in aquatic ecosystems? A review of nitrate removal pathways. Front Ecol Environ 5:89-96

> Carlson CA, Bates NR, Ducklow HW, Hansell DA (1999) Estimation of bacterial respiration and growth efficiency in the Ross Sea, Antarctica. Aquat Microb Ecol 19:229-244

$>$ Chen H, Allgower F (1998) A quasi-infinite horizon nonlinear model predictive control scheme with guaranteed stability. Automatica 34:1205-1217

Christen T (2006) Application of the maximum entropy production principle to electrical systems. J Phys D Appl Phys 39:4497-4503

Clausius R (1850) Über die bewegende Kraft der Wärme und die Gesetze, welche sich daraus für die Wärmelehre selbst ableiten lassen. Ann Phys Chem 155:368-397

> Dale AW, Regnier P, Van Cappellen P (2006) Bioenergetic controls on anaerobic oxidation of methane (AOM) in coastal marine sediments: a theoretical analysis. Am J Sci 306:246-294

> Dalsgaard T, Thamdrup B, Canfield D (2005) Anaerobic ammonium oxidation (anammox) in the marine environment. Res Microbiol 156:457-464

del Giorgio P, Cole J (1998) Bacterial growth efficiency in natural aquatic systems. Annu Rev Ecol Syst 29:503-541

Engström P, Dalsgaard T, Hulth S, Aller R (2005) Anaerobic ammonium oxidation by nitrite (anammox): implications for $\mathrm{N}_{2}$ production in coastal marine sediments. Geochim Cosmochim Acta 69:2057-2065

Falkowski PG, Fenchel T, Delong EF (2008) The microbial engines that drive earth's biogeochemical cycles. Science 320:1034-1039

Fernández A, Huang S, Seston S, Xing J, Hickey R, Criddle C, Tiedje J (1999) How stable is stable? Function versus community composition. Appl Environ Microbiol 65: 3697-3704

> Froelich P, Klinkhammer G, Bender M, Luedtke N and others (1979) Early oxidation of organic matter in pelagic sediments of the Eastern Equatorial Atlantic-suboxic diagenesis. Geochim Cosmochim Acta 43:1075-1090

Galloway J, Dentener F, Capone D, Boyer E and others (2004) Nitrogen cycles: past, present, and future. Biogeochemistry 70:153-226

> Gao H, Schreiber F, Collins G, Jensen MM and others (2010) Aerobic denitrification in permeable Wadden Sea sediments. ISME J 4:417-426

> Gentleman W (2002) A chronology of plankton dynamics in silico: how computer models have been used to study marine ecosystems. Hydrobiologia 480:69-85

> Gnaiger E (1990) Concepts on efficiency in biological calorimetry and metabolic flux control. Thermochim Acta 172:31-52

Graham DW, Knapp CW, Van Vleck ES, Bloor K, Lane TB, Graham CE (2007) Experimental demonstration of chaotic instability in biological nitrification. ISME J 1 : 385-393

Güven D, Dapena A, Kartal B, Schmid M and others (2005) Propionate oxidation by and methanol inhibition of anaerobic ammonium-oxidizing bacteria. Appl Environ Microbiol 71:1066-1071

Hill A (1990) Entropy production as the selection rule between different growth morphologies. Nature 348: $426-428$

Iverson V, Morris RM, Frazar CD, Berthiaume CT, Morales RL, Armbrust EV (2012) Untangling genomes from metagenomes: revealing an uncultured class of marine Euryarchaeota. Science 335:587-590

Jin Q, Bethke C (2003) A new rate law describing microbial respiration. Appl Environ Microbiol 69:2340-2348

- Kleidon A (2009) Nonequilibrium thermodynamics and maximum entropy production in the Earth system. Naturwissenschaften 96:653-677

- Kleidon A (2010a) Life as the major driver of planetary geochemical disequilibrium. Reply to comments on 'Life, hierarchy, and the thermodynamic machinery of planet Earth'. Phys Life Rev 7:473-476

> Kleidon A (2010b) Life, hierarchy, and the thermodynamic machinery of planet Earth. Phys Life Rev 7:424-460

Kleidon A, Malhi Y, Cox PM (2010) Maximum entropy production in environmental and ecological systems. Philos Trans R Soc Lond B Biol Sci 365(Suppl I):1297-1302

Konopka A (2009) What is microbial community ecology? ISME J 3:1223-1230

LaRowe DE, Dale AW, Amend JP, Van Cappellen P (2012) Thermodynamic limitations on microbially catalyzed reaction rates. Geochim Cosmochim Acta 90:96-109

> Lendenmann U, Egli T (1998) Kinetic models for the growth of Escherichia coli with mixtures of sugars under carbonlimited conditions. Biotechnol Bioeng 59:99-107

> Lorenz R, Lunine J, Withers P, McKay C (2001) Titan, Mars and Earth: entropy production by latitudinal heat transport. Geophys Res Lett 28:415-418 
Lotka AJ (1922) Contribution to the energetics of evolution. Proc Natl Acad Sci USA 8:147-151

- Mayne D, Rawlings J, Rao C, Scokaert R (2000) Constrained model predictive control: stability and optimality. Automatica 36:789-814

Meysman FJR, Bruers S (2007) A thermodynamic perspective on food webs: quantifying entropy production within detrital-based ecosystems. J Theor Biol 249: 124-139

Meysman FJR, Bruers S (2010) Ecosystem functioning and maximum entropy production: a quantitative test of hypotheses. Philos Trans R Soc Lond B Biol Sci 365(Suppl I):1405-1416

Paerl HW, Dennis RL, Whitall DR (2002) Atmospheric deposition of nitrogen: implications for nutrient over-enrichment of coastal waters. Estuaries Coasts 25:677-693

Paltridge GW (1975) Global dynamics and climate - a system of minimum entropy exchange. Q J R Meteorol Soc 101: 475-484

$>$ Pfeiffer T, Bonhoeffer S (2002) Evolutionary consequences of tradeoffs between yield and rate of ATP production. Z Phys Chem 216:51-63

Powell M (2010) The BOBYQA algorithm for bound constrained optimization without derivatives. Optimization Online 5:1-39

Rabalais NN, Turner RE, Wiseman WJ (2001) Hypoxia in the Gulf of Mexico. J Environ Qual 30:320-329

Rysgaard S, Glud R, Risgaard-Petersen N, Dalsgaard T (2004) Denitrification and anammox activity in Arctic marine sediments. Limnol Oceanogr 49:1493-1502

Schrödinger E (1944) What is life? Cambridge University Press, Cambridge

Seitzinger SP (1988) Denitrification in freshwater and

Editorial responsibility: Antje Boetius,

Bremen, Germany coastal marine ecosystems: ecological and geochemical significance. Limnol Oceanogr 33:702-724

Shimokawa S, Ozawa H (2001) On the thermodynamics of the oceanic general circulation: entropy increase rate of an open dissipative system and its surroundings. Tellus Ser A Dyn Meterol Oceanogr 53:266-277

Simon C, Daniel R (2011) Metagenomic analyses: past and future trends. Appl Environ Microbiol 77:1153-1161

> Strous M, Kuenen J, Jetten M (1999) Key physiology of anaerobic ammonium oxidation. Appl Environ Microbiol 65:3248-3250

Strous M, Pelletier E, Mangenot S, Rattei T and others (2006) Deciphering the evolution and metabolism of an anammox bacterium from a community genome. Nature 440 : 790-794

Swenson R (1989) Emergent attractors and the law of maximum entropy production: foundations to a theory of general evolution. Syst Res 6:187-197

Thamdrup B, Dalsgaard T (2002) Production of $\mathrm{N}_{2}$ through anaerobic ammonium oxidation coupled to nitrate reduction in marine sediments. Appl Environ Microbiol 68: $1312-1318$

Vallino JJ (2010) Ecosystem biogeochemistry considered as a distributed metabolic network ordered by maximum entropy production. Philos Trans R Soc Lond B Biol Sci 365:1417-1427

> Vallino JJ (2011) Differences and implications in biogeochemistry from maximizing entropy production locally versus globally. Earth Syst Dyn 2:69-85

$>$ van Niftrik LA, Fuerst JA, Damste JS, Kuenen JG, Jetten MS, Strous M (2004) The anammoxosome: an intracytoplasmic compartment in anammox bacteria. FEMS Microbiol Lett 233:7-13

Submitted: March 22, 2013; Accepted: November 11, 2013 Proofs received from author(s): January 15, 2014 